\title{
Syntheses, Characterization and Study of the Use of Cobalt (II) Schiff-Base Complexes as Catalysts for the Oxidation of Styrene by Molecular Oxygen
}

\author{
Ali Akbar Khandar ${ }^{1}$, Kamellia Nejati ${ }^{2, *}$ and Zolfaghar Rezvani ${ }^{3}$ \\ ${ }^{1}$ Department of Inorganic Chemistry, Faculty of Chemistry, Tabriz University, Tabriz, Iran \\ ${ }^{2}$ Payam Noor University -Tabriz Center, Emamieh ,Hakimnezami Street, Tabriz, Iran \\ ${ }^{3}$ Department of Chemistry, Faculty of Science, Azarbaijan University of Tarbiat Moallem, Tabriz, \\ Iran
}

* Author to whom correspondence should be addressed: Fax: (+98) 411 5412108; Tel: (+98) 411 5412117; e-mail:nejati_k@yahoo.com.

Received: 13 August 2004 / Accepted: 14 September 2004 / Published: 31 January 2005

\begin{abstract}
Schiff-Base complexes of bis-5-phenylazosalicylaldehyde ethylenediimine and bis-5-phenylazosalicylaldehyde-O-phenylenediimine ligands with $\mathrm{Co}$ (II) (I and II) have been synthesized and characterized by their IR spectra and elemental analyses. These complexes catalyze the oxidation of styrene in the presence of dioxygen and excess pyridine. The effect of the reaction conditions on the oxidation of styrene was studied by varying solvent, nature and amount of the catalyst and substrate. The catalytic behavior of the studied complexes was shown to be dependent on the conditions applied. In all reactions, acetophenone and 1- phenylethanol were the only observed products.
\end{abstract}

Keywords: Cobalt, Schiff base complexes, Salicylidene, Styrene, Oxidation

\section{Introduction}

The ability of certain cobalt (II) complexes to reversibly bind dioxygen was discovered many decades ago [1,2]. Since then, many cobalt(II) dioxygen carriers have been discovered $[3,4]$. Some of them have properties which make them good candidates for industrial and/or medicinal applications. Oxidations of organic molecules with dioxygen transition metal complexes have been extensively studied in view of the potential for exploitation of new synthetic methodologies and as an aid to the 
understanding of biological oxidation mechanisms $[5,6]$. On the other hand, controlled oxidation of organic compounds with molecular oxygen is a hotly pursued approach for the development of environmentally benign and ecologically sustainable chemical processes. These processes are significant in the preparation of organic reagents [7], bleaching of paper pulp [8] or textiles [9], chemicals raw materials industries [10] and environmental catalysis. We describe here the synthesis and characterization of some complexes of cobalt (II) with tetracoordinate Schiff-base ligands (I and II, Figure 1). We also report the oxidation of styrene by molecular oxygen in the presence of excess aromatic base to the corresponding 2-ketone and 2-alcohol using the complexes I and II as catalysts.

\section{Figure 1}

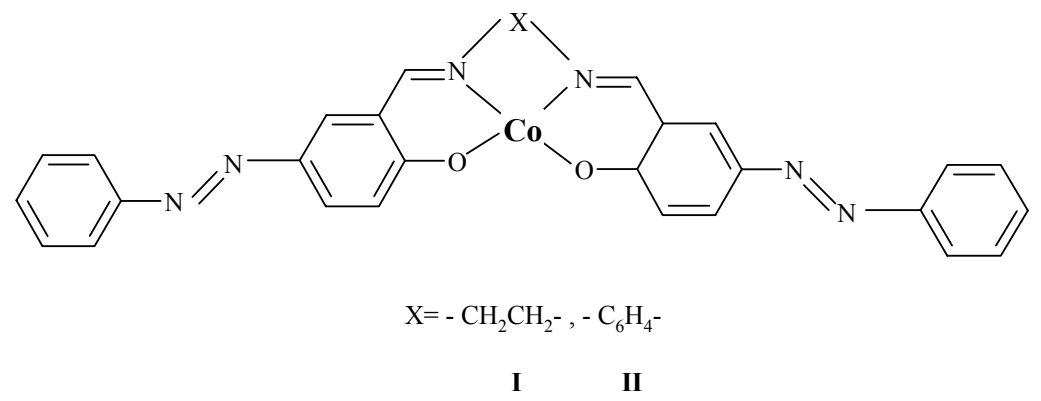

\section{Results and Discussion}

Synthesis

All ligands and complexes were obtained in good yield and purity. Cobalt complexes were characterized by elemental analysis and IR spectroscopy. All characterization data for the complexes is given in Table 1.

Table 1 Characterization data for complexes I and II

\begin{tabular}{|c|c|c|}
\hline Complex & I & II \\
\hline Yield (\%) & 90 & 89 \\
\hline \multicolumn{3}{|c|}{ IR data $\left(\mathrm{cm}^{-1}\right)$} \\
\hline$U_{C-H(a r o m a t i c)}$ & 3040 & 3050 \\
\hline UC-H(aliphatic) & 2920 & - \\
\hline$v_{\mathbf{C}=\mathbf{N}}$ & 1600 & 1600 \\
\hline$v_{\mathrm{C}=\mathrm{C}}$ & 1590 & 1585 \\
\hline$U_{N}=\mathbf{N}$ & 1525 & 1520 \\
\hline \multicolumn{3}{|c|}{ Analyses, found (calc.) } \\
\hline $\mathrm{C}$ & $62.81(63.04)$ & $65.73(66.09)$ \\
\hline $\mathbf{H}$ & $3.75(4.10)$ & $3.59(3.78)$ \\
\hline $\mathbf{N}$ & $15.48(15.75)$ & $14.30(14.45)$ \\
\hline
\end{tabular}


In the IR spectra of the complexes $v_{\mathrm{C}=\mathrm{N}}$ was shifted to a lower wavenumber by ca. $10-40 \mathrm{~cm}^{-1}$ upon coordination. In addition, the disappearance of the $\mathrm{OH}$ band of the free ligands in the cobalt (II) complexes indicates that the $\mathrm{OH}$ group has become deprotonated and bonded to the metal ion as $-\mathrm{O}^{-}$. On the basis of these results it can be concluded that in the complexes I and II, the Schiff-bases are coordinated to the cobalt atom as tetradentate ONNO ligands. The coordination spheres of our complexes are similar to those of cobalt salen-type complexes that have been reported to be squareplanar [11-13], therefore we suggest that the title complexes I and II also possess similar squareplanar structures.

\section{Catalytic Properties}

The catalytic properties of complexes I and II were investigated in the oxidation reaction of styrene in the presence of pyridine as axial base under different experimental conditions. The only products formed were acetophenone and 1-phenylethanol. The salen-type complexes of cobalt(II) have been known for a long time as dioxygen activators [10,14-18].

Four-coordinate square-planar cobalt salen-type complexes need an added base, which binds to the axial position of the coordination sphere of the central metal $[10,19,20]$. The trans axial ligand enhances the oxygen binding capability of the square-planar complexes and stabilizes the formed dioxygen adducts [19]. The most commonly utilized axial base in cobalt salen-type catalytic oxidation systems is pyridine $[10,20]$. $\mathrm{Co}$ (salen) and similar compounds react reversibly with oxygen to give an equilibrium mixture of a superoxo complex $\left(\mathrm{Co}: \mathrm{O}_{2}\right.$ ratio $\left.1: 1\right)$ and a dimeric peroxo complex $\left(\mathrm{Co}: \mathrm{O}_{2}\right.$ ratio $2: 1$ ) $[10,14,21]$. The formation of these species (superoxo or $\mu$-peroxo) depends on the reaction conditions $[17,22]$.

Many of the observed effects of reaction conditions can be explained by the altered equilibrium of these two species. The formation of superoxo complex is favored in the most polar solvents [19]. On the other hand, high temperatures favor the peroxo- bridged species, while low temperatures [for example $(-70)^{\circ} \mathrm{C}-25^{\circ} \mathrm{C}$ ] favor $1: 1$ dioxygen adduct formation, which can be explained by the different thermal parameters for 1:1 and 2:1 adduct formation [23-26]. Therefore it can be suggested that our complexes also, with respect to the temperature $\left(70^{\circ} \mathrm{C}\right)$, act as $\mu$-peroxo dimers.

Several reaction conditions were varied to study their effect on the oxidation activity of the catalytic system. These variables included the added solvent, axial base, nature and concentration of catalyst and substrate. The different experimental conditions used, \% yields of the products and styrene conversions to these products, turnover numbers of the reactions and the [acetophenone]/[1phenylethanol] ratios (which are representative of reaction selectivity) after 8 hours are summarized in Table 2 . 
Table 2. The $\%$ of the products and styrene conversion to the products, turnover number of reactions and [acetophenone]/[1- phenylethanol] ratio after $8 \mathrm{~h}$ under different experimental conditions.

\begin{tabular}{|c|c|c|c|c|c|c|c|c|}
\hline \multirow{2}{*}{$\begin{array}{c}\text { Experiment } \\
\text { No. }\end{array}$} & \multirow[b]{2}{*}{ Catalyst } & \multirow{2}{*}{$\begin{array}{c}\text { Substrate } \\
(\mathrm{ml})\end{array}$} & \multirow[b]{2}{*}{ Solvent } & \multicolumn{2}{|c|}{ Products $(\%)$} & \multirow{2}{*}{$\begin{array}{c}\text { Styrene } \\
\text { conversion } \\
(\%)\end{array}$} & \multirow{2}{*}{$\begin{array}{c}\text { Turnover } \\
\text { number }\end{array}$} & \multirow{2}{*}{$\begin{array}{l}\text { [ketone]/ } \\
\text { [alcohol] }\end{array}$} \\
\hline & & & & Ketone & Alcohol & & & \\
\hline 1 & $\mathrm{II}(0.25 \mathrm{~g})$ & 3 & $\mathrm{EtOH}$ & 81.78 & 18.22 & 19.75 & 11.94 & 4.49 \\
\hline 2 & $\mathrm{II}(0.25 \mathrm{~g})$ & 3 & 1-PrOH & 93.72 & 6.28 & 13.54 & 8.19 & 14.93 \\
\hline 3 & $\mathrm{II}(0.25 \mathrm{~g})$ & 3 & 2-PrOH & 61.40 & 35.90 & 2.53 & 1.53 & 1.78 \\
\hline 4 & $\mathrm{II}(0.25 \mathrm{~g})$ & 6 & 1-PrOH & 84.90 & 15.10 & 5.73 & 5.12 & 5.63 \\
\hline 5 & $\mathrm{II}(0.5 \mathrm{~g})$ & 3 & 1-PrOH & 100.00 & - & 5.80 & 1.75 & $\infty$ \\
\hline 6 & $\mathrm{II}(0.25 \mathrm{~g})$ & 6 & $\mathrm{EtOH}$ & 54.12 & 45.88 & 4.18 & 5.06 & 1.18 \\
\hline 7 & $\mathrm{II}(0.5 \mathrm{~g})$ & 3 & $\mathrm{EtOH}$ & 100.00 & - & 2.69 & 0.81 & $\infty$ \\
\hline 8 & $\mathrm{I}(0.25 \mathrm{~g})$ & 3 & $\mathrm{EtOH}$ & 84.13 & 15.87 & 10.42 & 5.78 & 5.30 \\
\hline 9 & $\mathrm{I}(0.25 \mathrm{~g})$ & 3 & 1-PrOH & 83.10 & 16.90 & 2.66 & 1.47 & 5.00 \\
\hline 10 & $\mathrm{I}(0.25 \mathrm{~g})$ & 3 & 2-PrOH & 86.82 & 13.18 & 12.14 & 6.73 & 6.59 \\
\hline 11 & $\mathrm{I}(0.25 \mathrm{~g})$ & 6 & 2-PrOH & 80.79 & 19.21 & 1.07 & 1.19 & 4.58 \\
\hline 12 & $\mathrm{I}(0.5 \mathrm{~g})$ & 3 & 2-PrOH & 82.00 & 18.00 & 2.92 & 0.81 & 4.55 \\
\hline
\end{tabular}

$\mathrm{P}=1 \mathrm{~atm}, \mathrm{~T}=70^{\circ} \mathrm{C}$, substrate $=$ styrene, internal standard $=2$-octanone, alcohol $=1$-phenylethanol, ketone $=$ acetophenone, turnover numbers of reactions are calculated as the number of moles of substrate oxidized by $1 \mathrm{~mol}$ of the catalyst. The axial base is pyridine.

\section{The effect of the solvent}

In Figures 1 and 2 functional changes of the [acetophenone]/[1- phenylethanol] ratios in terms of the time for experiments 1, 2, 3 and 8, 9, 10 are shown for complexes II and I, respectively.

Figure 1. Variation of the [acetophenone]/[1-phenylethanol] ratio vs. time for experiments 1,2 and 3

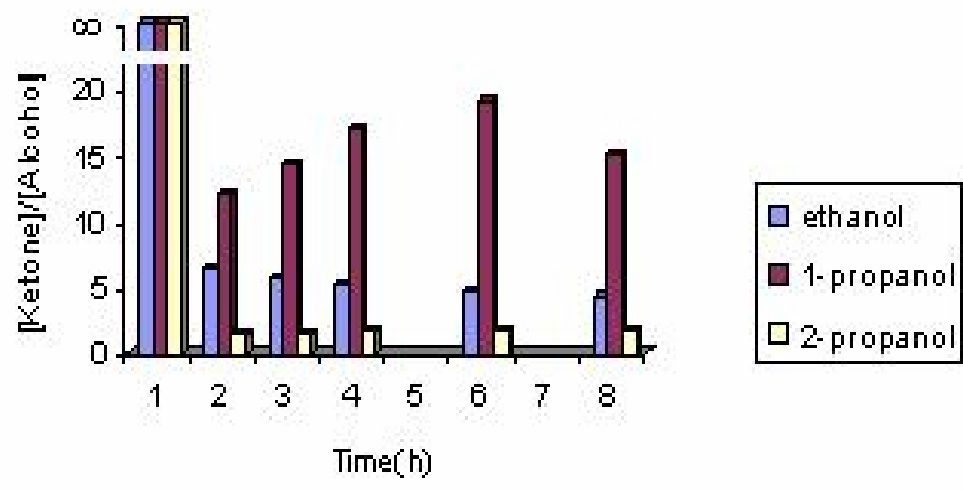


Figure 2. Variation of the [acetophenone $] /[1-$ phenylethanol] ratio vs. time for experiments 8,9 and 10

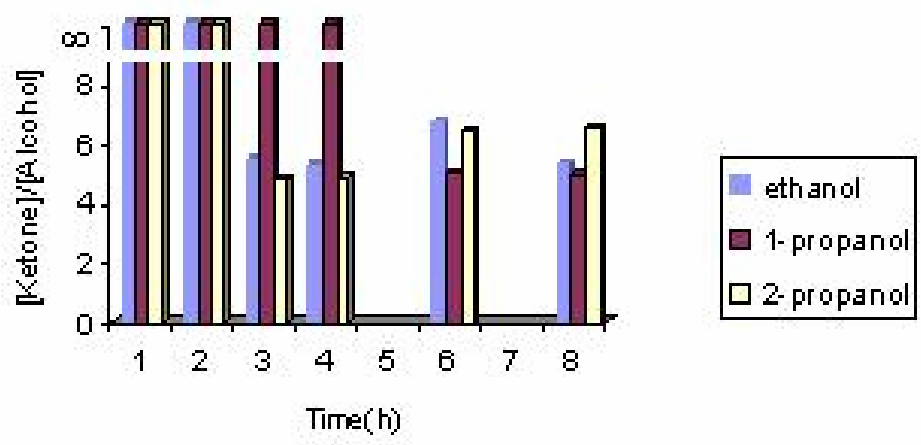

When the [acetophenone] /[1-phenylethanol] ratio is $\infty$ this means that we have only one product (acetophenone) and the reaction is completely selective. The functional changes of the 1phenylethanol and acetophenone concentration in terms of the time for experiments 1, 2, 3 and 8, 9, 10 are shown in Figures 3, 4, 5 and 6 respectively. From Figures 1 and 2 it can be concluded that complex II in 1-propanol has more selectivity than in the other two solvents. But in the case of complex I, in 1-propanol the reaction is completely selective for the first 4 hours. The yields of 1-phenylethanol and acetophenone production in the presence of complex II as catalyst in ethanol are greater than the yields of the reaction in the other solvents (Figures 3 and 4) and for complex I, in 1-propanol the yields are less than in the other two solvents (Figures 5 and 6) after 8 hours.

Figure 3. Variation of the 1-phenylethanol concentration vs. time for experiments 1, 2 and 3 . The concentration unit in axial axis is $\mathrm{M} \times 10^{4}$.

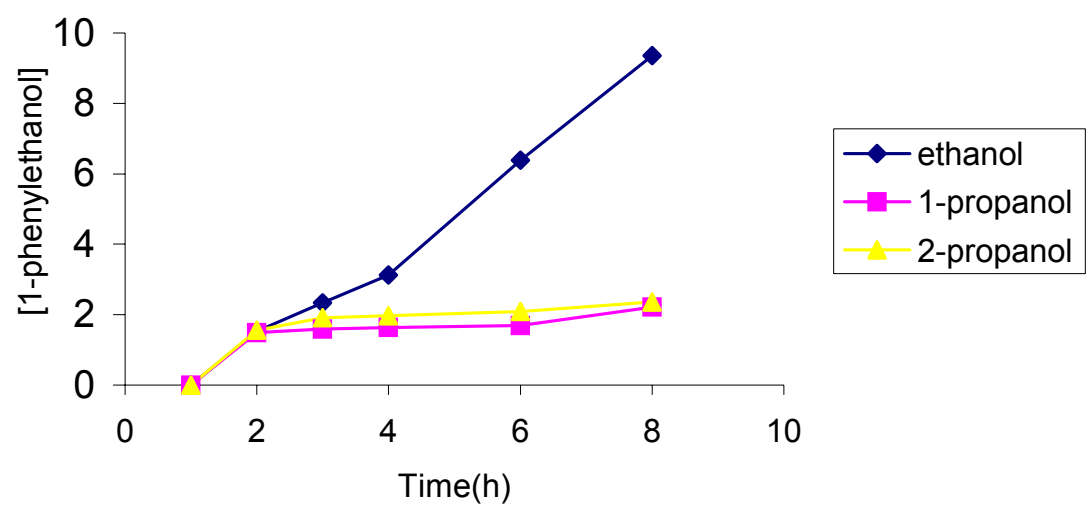


Figure 4. Variation of [acetophenone] vs. time for experiments 1, 2 and 3.
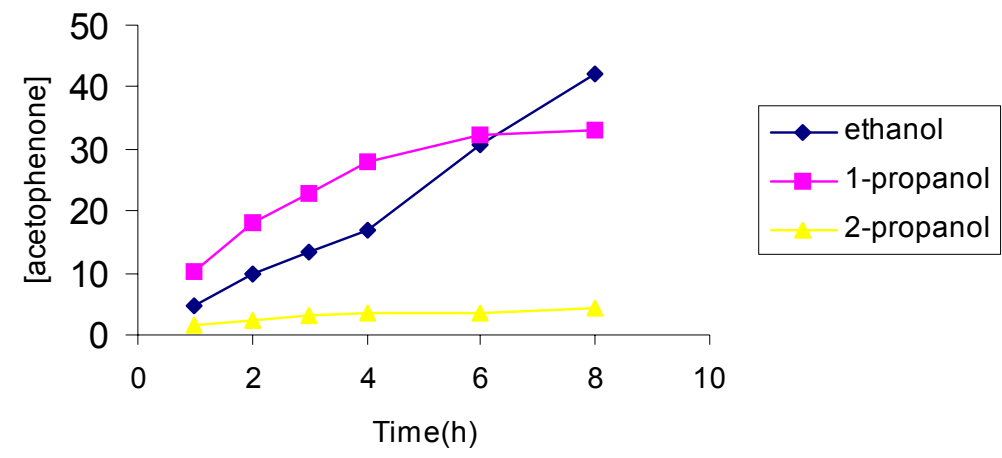

Figure 5. Variation of [1-phenylethanol] vs. time for experiments 8, 9 and 10 .
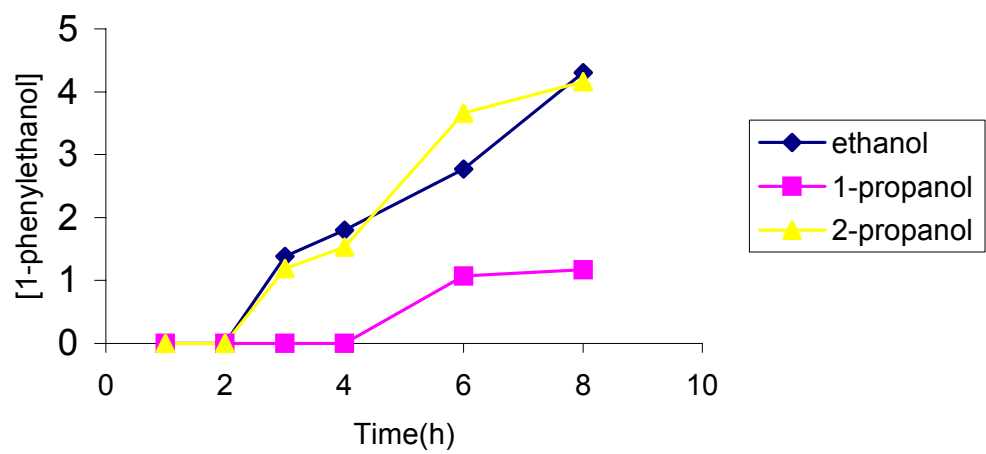

Figure 6. Variation of [acetophenone] vs. time for experiments 8, 9 and 10
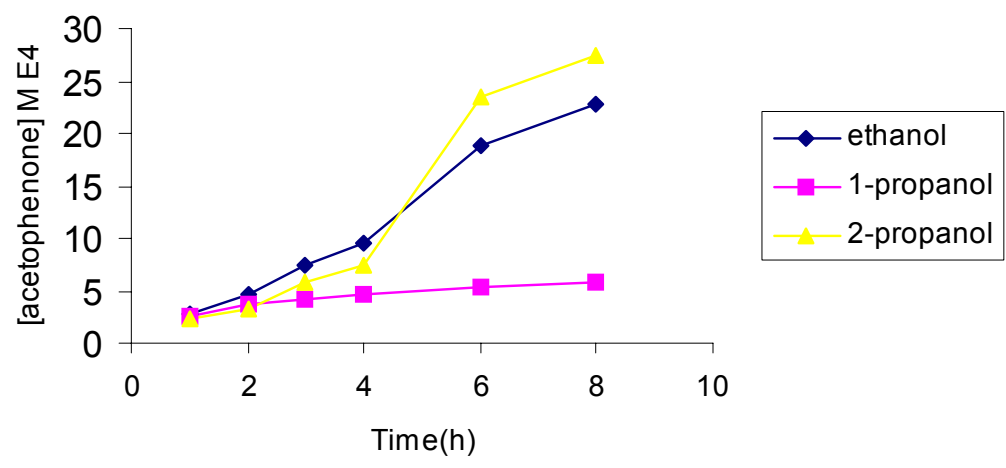
The effect of the catalyst

In experiments 1 and 8,2 and 9 and 3 and 10 the selectivity of the reactions varies as the complex is changed. In Figures 7, 8 and 9 the changes of selectivity of the reactions in terms of the time for these experiments are shown.

Figure 7. Variation of the [acetophenone]/[1-phenylethanol] ratio vs. time for experiments 1 and 8 .

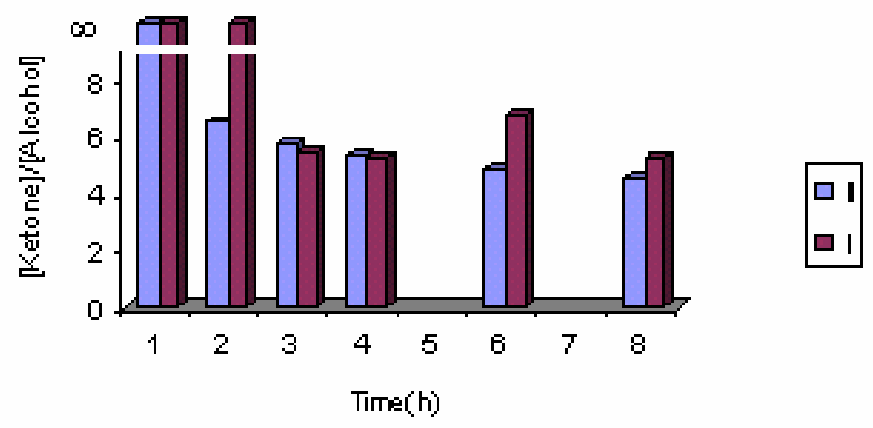

From Figures 7, 8 and 9 it can be concluded that complex I has more selectivity than complex II in ethanol and 2-propanol but in 1-propanol complex I reacts with completely selectivity up to 4 hours and then its selectivity decreases and eventually becomes less than that seen with complex II.

Figure 8. Variation of the [acetophenone]/[1- phenylethanol] ratio vs. time for experiments 2 and 9.
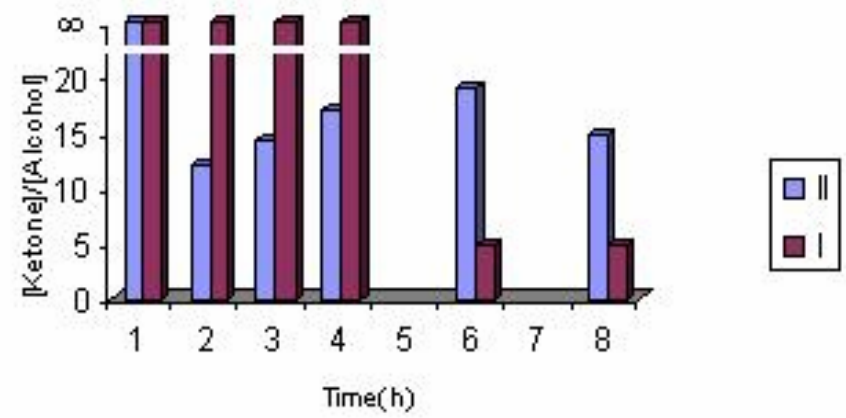

Figure 9. Variation of the [acetophenone] / [1-phenylethanol ] ratio vs. time for experiments 3 and 10

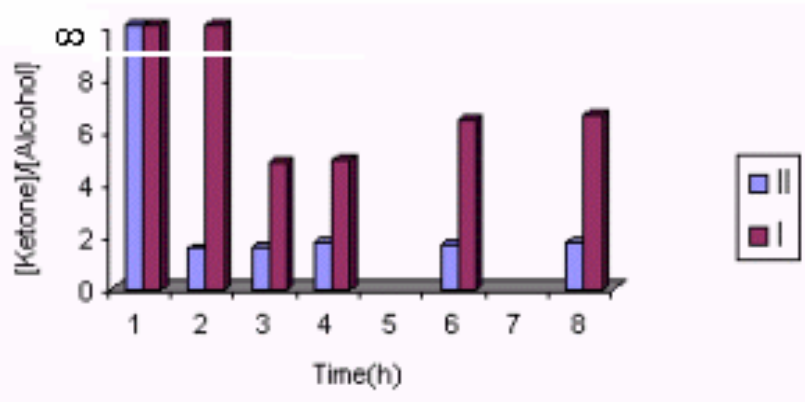




\section{The effect of catalyst concentration}

For complex II, the changes of selectivity of the reactions in terms of the time in experiments 1 and 7 and 2 and 5 are shown in Figures 10 and 11, respectively. These figures show that the selectivity of complex II increases with an increase in the catalyst concentration in ethanol and 1-propanol, whereas the selectivity of complex $\mathbf{I}$ in 2-propanol (experiments 10 and 12) decreases when the catalyst concentration is increased (Figure 12).

Figure 10. Variation of the [acetophenone]/[1-phenylethanol] ratio vs. time in experiments 1 and 7

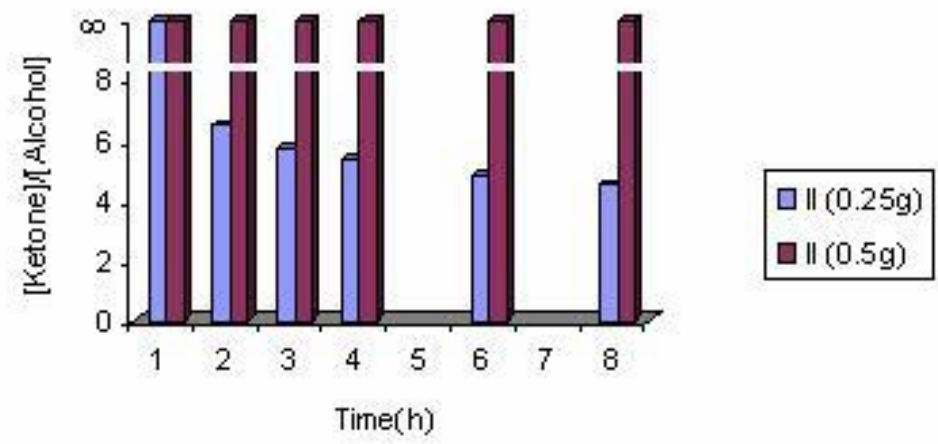

Figure 11. Variation of the [acetophenone]/[1-phenylethanol] ratio vs. time in experiments 2 and 5.

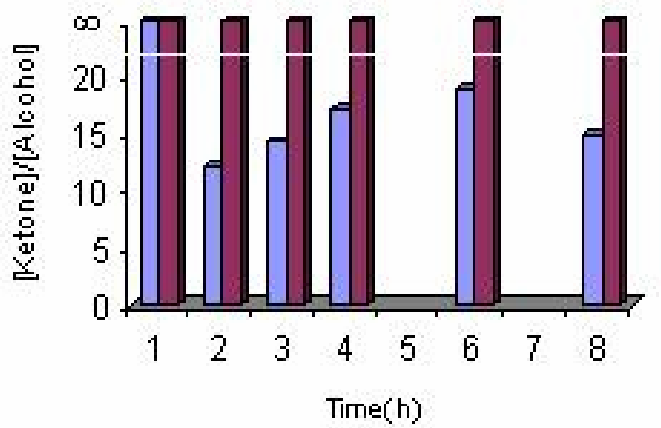

Figure 12. Variation of the [acetophenone]/[1-phenylethanol] ratio vs. time in experiments 10 and 12

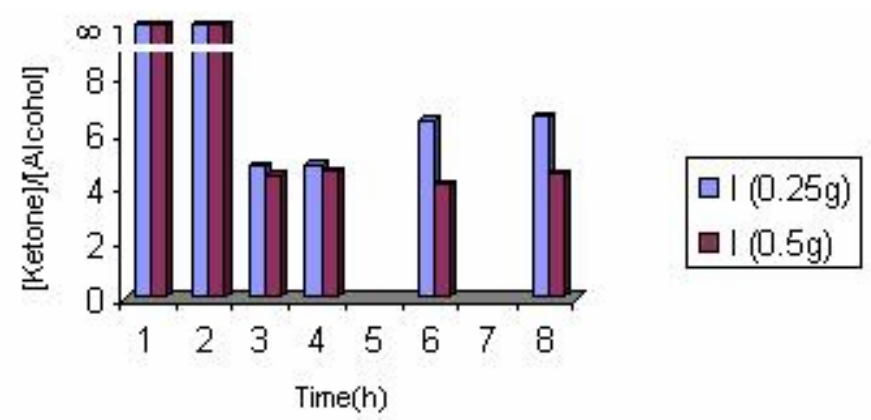




\section{Conclusions}

The Co(II) complexes I and II catalyze the oxidation of styrene in the presence of $\mathrm{O}_{2}$ and excess pyridine. In all reactions, acetophenone and 1- phenylethanol were the only observed products. The catalytic activities were shown to depend on the conditions used, as complex II was more selective in 1-propanol than in other solvents, whereas in the case of complex $\mathbf{I}$, the reaction was $100 \%$ selective in 1-propanol for the first 4 hours. With complex II the reaction becomes $100 \%$ selective upon increasing the catalyst concentration in ethanol and 1-propanol. On the other hand, in the case of complex I, the selectivity of the reaction in 2-propanol decreases when the catalyst concentration increases.

\section{Acknowledgements}

We thank Professor M.T. Zaaferani, Professor J. Manzouri and Dr A. Shahrisa for their useful suggestions and Azarbaijan University of Tarbiat Moalem, for GC spectra.

\section{Experimental}

\section{General}

All reagents and solvents were used as supplied by Merck. Absolute ethanol, anhydrous 1propanol and 2-propanol were stored over $3 \AA$ and $4 \AA$ molecular sieves and used without further purification. Styrene and pyridine were distilled and stored over $4 \AA$ molecular sieves. 5-Phenylazo salicylaldehyde and the ligands were obtained as described elsewhere [27]. Elemental (C, H and N) analyses were done on a Perkin - Elmer model 240B automatic instrument. Infrared spectra were recorded on IR 408 Shimadzu 568 instrument. GC spectra were recorded on a Philips model P44410 gas chromatograph equipped with a flame ionization detector, using a stainless steel column packed with OPEG 20 M \% diethylene glycol adipate on Chromosorb P.

\section{Complexes}

The complexes were prepared in similar manner. The ligand $(0.004 \mathrm{~mol})$ was mixed with $\mathrm{Co}(\mathrm{acac})_{2} \cdot 4 \mathrm{H}_{2} \mathrm{O}(0.004 \mathrm{~mol})$ and refluxed in ethanol $(100 \mathrm{~mL})$ for $1 \mathrm{~h}$. The mixture was then cooled, filtered and resulting complex was washed with ethanol and ether and dried under vacuum at $100^{\circ} \mathrm{C}$.

\section{Oxidation Reactions}

The oxidation reactions were carried out in $250 \mathrm{~mL}$ flask containing a magnetic stir bar, fitted with a pressure gauge and placed in a temperature controlled oil bath inside a steel explosion shield. For a typical oxidation, solvent $(25 \mathrm{~mL})$, substrate $(3 \mathrm{~mL})$, pyridine $(5 \mathrm{~mL})$, 2-octanone $(0.28 \mathrm{~mL}$, internal GC standard) and a plastic cap containing the catalyst $(0.25 \mathrm{~g})$ were added to the flask, which was attached to the pressure head and placed in the oil bath at $70^{\circ} \mathrm{C}$ (the complexes are insoluble below this temperature). The system was then purged several times with oxygen. Stirring was begun to capsize the catalyst-containing cap and initiate the oxidation. The progress of the reactions was monitored by injecting an aliquot of sample $(0.4-0.5 \mu \mathrm{L})$ into the GC for analysis. The amounts of products present were calculated from calibration curves based on the 2- octanone standard. 


\section{References}

1. Werner, A.; Mylius, A.Z. Anorg. Allg. Chem. 1898, 16, 245.

2. Tsumaki, T. Bull. Chem. Soc. Jpn. 1938, 13, 252.

3. Busch, D.H.; Alcock, N.W. Chem. Rev. 1994, 94, 585.

4. Niederhoffer, E.C.; Timmons, J.H.; Martell, A.E. Chem. Rev. 1984, 84, 137.

5. Jones, R.D.; Summerville, D.A.; Basolo, F. Chem. Rev. 1979, 79, 139.

6. Mimoun, H. J. Mol. Cat. 1980, 7, 1.

7. Ebner, J.; Riley, D.; Foote, C.S.; Valentine, J.S.; Greenberg, A.; Liebman, J.F. (Eds.); Active Oxygen in Chemistry, SEARCH Series, Vol. 2; Blackie Academic and Professional Publishers: Glasgow, U.K, 1995; Chap. 6, p. 205.

8. Cui, Y.; Patt, R.; Chen, R.; Gratzl, J. J. Mol. Catal. A 1999, 144, 411.

9. Hage, R.; Iburg, J.E.; Koek, J.H.; Martens, R.; Kerschner, J.; Lempers, E.L.M.; Martens, R.J.; Racheria,U.S.; Russell, S.W.; Swaryhoff, T.; van Vliet, M.R.P.; Warnaar, J.B.; van der Wolf, L.; Krijnen, B. Nature. 1994, 369, 637.

10. Bozell, J.; Hames, B.R.; Dimmel, D.R. J. Org. Chem. 1995, 60, 2398.

11. Nishinaga, A.; Tsutsui, T.; Moriyama, H.; Wazaki, T.; Mashino, T.; Fujii, Y. J. Mol. Catal. 1993, $83,117$.

12. Vogt Jr, L.H.; Faigenbaum, H.M.; Wiberley, S.E. Chem. Rev. 1963, 63, 269.

13. Kervinen, K.; Lahtinen, P.; Repo, T.; Svahn, M.; Leskela, M. Catal. Today 2002, 75, 183.

14. Sheldon, R.A.; Kochi, J.K. Metal-Catalyzed Oxidation of Organic Compounds; Academic Press: New York, 1981; p.97.

15. Drago, R.S.; Corden, B.B. Acc. Chem. Res. 1980, 13, 353.

16. Corden, B.B.; Drago, R.S.; Perito, R.P. J. Am. Chem. Soc.1985, 107, 2903.

17. Martell, A.E. Oxygen Complexes and Oxygen Activation by Transition Metals; Plenum Press: New York, 1987; p.87.

18. McLendon, G., Martell, A.E. Coord. Chem. Rev. 1976, 19, 1.

19. Sasaki, I.; Pujol, D.; Gaudemer, A. New J. Chem. 1989, 13, 843.

20. Jager, E.G.; Knaudt, J.; Rudolph, M.; Rost, M. Chem. Ber. 1996, 129, 1041.

21. Lippard, S.; Feig, A. Chem. Rev. 1994, 94, 759.

22. Henson, N.J.; Hay, P.J.; Redondo, A. Inorg. Chem. 1999, 38, 1618.

23. Chen, D.; Martell, A.E. Inorg. Chem. 1987, 26, 1026.

24. Chen, D.; Martell, A.E.; Sun, Y. Inorg. Chem.1989, 28, 2647.

25. Nakamoto, K.; Nonaka, Y.; Ishiguro, T.; Urban, W.M.; Suzuki, M.; Kozuka, M.; Nishida,Y.; Kida, S. J. Am. Chem. Soc. 1982, 104, 3386.

26. Stynes, D.V.; Stynes, H.C.; Ibers, J.A.; James, B.R. J. Am. Chem. Soc. 1973, 95, 1142.

27. Khandar, A.A.; Nejati, K. Polyhedron 2000, 19, 607.

Sample availability: Available from the authors.

(C) 2005 by MDPI (http://www.mdpi.org). Reproduction is permitted for noncommercial purposes. 